\title{
海河南系表层沉积物中多环芳烃的污染特征与 生态风险评价
}

\author{
刘丰，刘静玲"，陈秋颖，王滨滨，曹志国 \\ 北京师范大学环境学院, 水环境模拟国家重点实验室, 北京 100875 \\ *联系人, E-mail: jingling@bnu.edu.cn \\ 2012-08-15 收稿, 2013-01-07 接受, 2013-03-01 网络版发表 \\ 水体污染控制与治理重大科技专项(2011ZX07203-006)和国家自然科学基金(41271496)资助
}

\begin{abstract}
摘要 海河南系是海河流域面积最大的水系, 对海河流域的水生态系统健康和饮用水安全具 有重要意义. 为全面了解海河南系表层沉积物中多环芳烃的污染特征及生态风险, 分析了海 河南系自上游水库至河口 24 个表层沉积物样品中 16 种优先控制 PAHs 的污染特征和生态风险. 结果表明, PAHs 总量在 258.77 11296.66 ng/g 之间. 从16 种多环芳烃单体的组成来看, 2 环、3 环、4 环、5 环和 6 环多环芳烃分别占总量的 $25.32 \%, 27.22 \%, 22.62 \%, 14.89 \%$ 和 $9.96 \%$. 受附 近城市的影响, 府河、㵚阳河和卫河是PAHs 污染水平较高的河段. 生态风险评价结果表明, 单 体菜 (2.00) 和芘(1.67)最高风险熵值 $\left(\mathrm{RQ}_{\mathrm{MPCS}}\right)$ 大于 1 , 处于高风险水平, 其他各单体均处于中等 风险水平. 各采样点总 PAHs 的风险摘值计算表明, 大西洋水库和子牙河河口处于低风险水平, 保定、阻単和艾辛庄处于高风险水平.
\end{abstract}

关键词

多环芳烃

表层沉积物

海河南系

分布

组成

生态风险评价
多环芳烃(Polycyclic Aroatic Hydrocarbons, PAHs) 是一类具有潜在致癌、致畸、致突变效应的持久性有 机污染物，同时被美国环保局和欧盟列为优先污染 物 ${ }^{[1]}$. PAHs 主要来源于化石燃料和有机物的不完全 燃烧、石油产品的泄漏、森林火灾、火山活动等, 并 通过地表径流、干湿沉降进人环境水体 ${ }^{[2]}$. 水环境中 的 PAHs 因其溶解度低、辛醇-水分配系数高的特点, 易于与悬浮物结合而富集在水体沉积物中 ${ }^{[3]}$, 成为长 期的潜在污染源 ${ }^{[4]}$. 沉积物中的 PAHs 容易通过食物 网在生物体内富集 ${ }^{[5]}$, 对人类和其他生物的生存和发 展构成潜在威胁 ${ }^{[6]}$. 因此, 沉积物中的多环芳烃受到 广泛的关注 ${ }^{[7,8]}$. 目前关于海河流域河流 PAHs 的研 究主要集中在京津地区的城市河段 ${ }^{[9,10]}$, 关于海河流

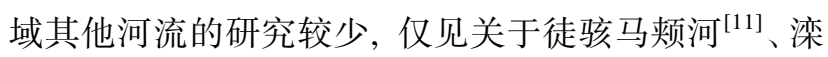
河 ${ }^{[12]}$ 和漳卫南运河 ${ }^{[13]}$ 地表水和沉积物中 PAHs 的分
布特征与生态风险的研究. 关于海河南系沉积物中 PAHs 的研究目前未见报道.

海河南系是海河流域最大的水系，由大清河、子 牙河和漳卫南运河组成, 流经石家庄、邯単、邢台、 保定等大城市，流域面积 $1.24 \times 10^{5} \mathrm{~km}^{2}$. 海河南系人 口稠密, 伴随着经济的高速发展, 海河南系水环境恶 化日益严重, 其中水体中的 PAHs 关系到海河南系部 分城市的饮用水安全问题, 但是目前并没有关于海 河南系多环芳烃污染特征的具体研究. 由于河流中 PAHs 多富集在沉积物中, 对海河南系河流表层沉积 物中 PAHs 污染特征的研究具有重要意义. 本研究通 过分析海河南系主要河流自上游至河口表层沉积物 PAHs 的浓度、组成和分布特征, 并对其进行生态风 险评价, 以期对海河南系持久性有机污染物的综合 治理提供理论基础和科学依据. southern part of the Haihe River system in China. Chin Sci Bull, 2013, 58, doi: 10.1007/s11434-013-5677-6 


\section{1 材料和方法}

(i ) 样品采集. 本研究共设置 24 个采样点, 具 体如图 1 所示. 其中 7 个采样点位于农村地区, 6 个位 于城市, 6 个位于水库, 3 个位于河口. 位于农村地区 的采样点不受工业和交通的直接影响, 可以反映研 究区内低人为干扰下较自然的 PAHs 浓度水平; 位于 城市的采样点则可以代表工业化和城市化导致的较 高的 PAHs 浓度水平; 水库等水资源保护区和河口则 对于饮用水安全和流域水资源管理具有重要意义.

2010 年 5 月对 24 个采样点进行了样品采集. 用 抓斗式采样器采集表层 $5 \mathrm{~cm}$ 沉积物, 并去除表层 $1 \mathrm{~cm}$ 作为样品, 置于甲醇清洗过的铝盒中 ${ }^{[14]}$, 运输过程 中用冰块和保温箱保持低温, 运回实验室后在 $-20^{\circ} \mathrm{C}$ 的条件下冷冻保存. 样品冷冻干燥后研磨过 100 目 篮 ${ }^{[15]},-20^{\circ} \mathrm{C}$ 冷藏备用. 每个采样点在 $5 \mathrm{~m}$ 内取 3 个平 行样, 混匀后作为一份样品以减小采样偶然性造成 的误差, 确保采集的样品可以真实反映采样点的污 染状况 ${ }^{[16,17]}$.

(ii) 样品预处理. 精确称取 $15 \mathrm{~g}$ 样品, 加人一 定量的回收率指示物(萮- $\mathrm{d} 8$ 、二氢苍- $\mathrm{d} 10$ 、菲- $\mathrm{d} 10$ 、

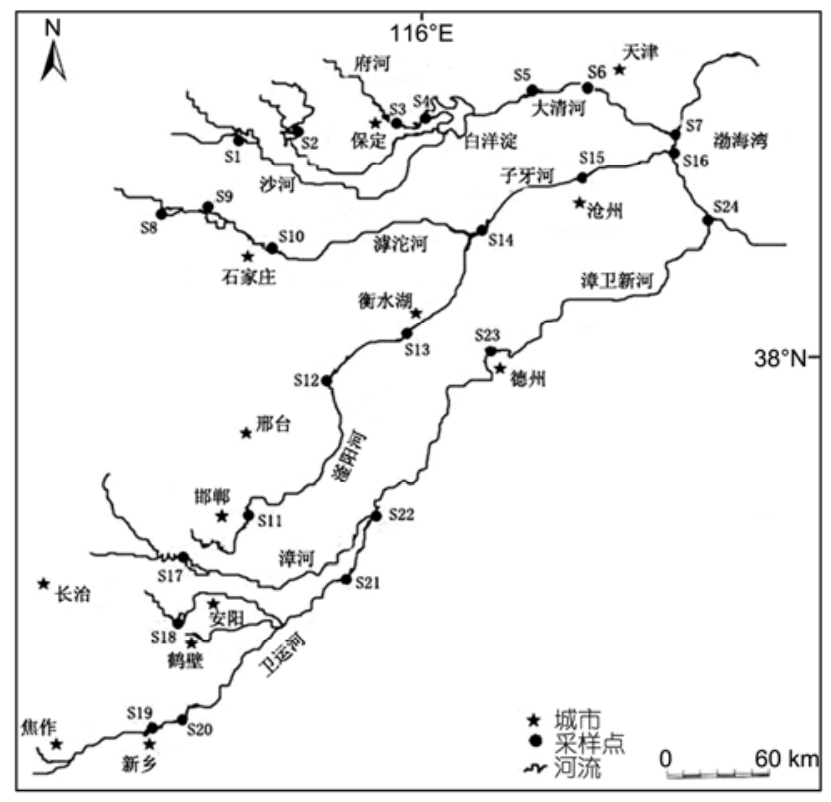

图 1 采样点分布图

$\mathrm{S} 1$, 王快水库; S2, 西大洋水库; S3, 保定; S4, 府河; S5, 霸州; S6, 静 海; S7, 海河河口; S8, 岗南水库; S9, 黄壁庄水库; S10, 石家庄; S11, 甘障; S12, 艾兴庄; S13, 衡水湖; S14, 献县; S15, 沧州; S16, 子牙河河 口; S17, 禹城; S18, 小南海水库; S19, 新乡; S20, 卫辉; S21, 龙王 庙; S22, 馆陶; S23, 德州; S24, 漳卫新河河口 屈-d12、菲-d12)，使用 $250 \mathrm{~mL}$ 正己烷与二氯甲烷 (1/1, $V / V)$ 的混合溶剂进行提取, 提取温度控制在 $60^{\circ} \mathrm{C}$, 回 流 $24 \mathrm{~h}$ 后回收提取液, 用旋转蒸发仪浓缩到 $2 \mathrm{~mL}$ 后 并经溶剂转换后, 在硅胶/氧化铝净化柱上净化, 用 $70 \mathrm{~mL}$ 二氯甲烷/正己烷 $(3 / 7, V / V)$ 洗脱得到多环芳烃 组分. 上述洗脱液再次用旋转蒸发仪浓缩到 $1 \mathrm{~mL}$, 加人 $2 \mathrm{~mL}$ 正已烷, 蒸发到 $0.5 \mathrm{~mL}$, 用正己烷溶液定 量转移到 KD 浓缩器刻度量管中, 添加多环芳烃内标 物六甲基苯 $10 \mu \mathrm{L}$ 并氮吹定容至 $1 \mathrm{~mL}$, 冷藏待用.

(iii) 仪器分析. PAHs 分析用气相色谱-质谱联 用仪 (GC/MS, HP6890/PH5973)测定. 选用 HP-5MS (30 $\mathrm{m} \times 0.25 \mathrm{~mm} \times 0.25 \mu \mathrm{m}$ ) 毛细管色柱, 恒流 $1.0 \mathrm{~mL} / \mathrm{min}$, 载气为 $\mathrm{He}$, 升温程序: 初温 $60^{\circ} \mathrm{C}$, 以 $6^{\circ} \mathrm{C} / \mathrm{min}$ 升至 $260^{\circ} \mathrm{C}$, 保持 $15 \mathrm{~min}$. 质谱的 $\mathrm{EI}$ 电离源为 $70 \mathrm{eV}$, 离子 源温度为 $280^{\circ} \mathrm{C}$, 扫描范围 45 400 amu, 通过 NIST 质谱库和色谱峰保留时间进行定性分析, 使用外标 法定量. 16 种检测的 PAHs 分别为: 菜 (Nap)、二氢苊 $(\mathrm{Ace}) 、$ 范 $(\mathrm{Acp}) 、$ 芴 $(\mathrm{Fl}) 、$ 菲 $(\mathrm{Phe}) 、$ 葸 $(\mathrm{An}) 、$ 苂葸 $(\mathrm{Flu}) 、$ 芘 $(\mathrm{Pyr}) 、$ 苯并 $(\mathrm{a})$ 蒽 $(\mathrm{BaA}) 、$ 屈 $(\mathrm{Chr}) 、$ 苯并 $(\mathrm{b})$ 菼蒽 $(\mathrm{BbF}) 、$ 苯并 $(k)$ 菼蒽 $(B k F)$ 、苯并 $(a)$ 萠 $(B a P)$ 、二苯并 $(a, h)$ 蒽 $(\mathrm{DbA}) 、$ 、狮并 $(1,2,3-\mathrm{cd})$ 芘 $(\mathrm{InP}) 、$ 、苯并 $(\mathrm{g}, \mathrm{h}, \mathrm{i})$ 芘 (BghiP).

(iv) 质量控制. 回收率指示物的回收率分别为: 萗-d8: $51.8 \% \pm 10.7 \%$, 二氢苍-d10: $78.6 \% \pm 10.9 \%$, 菲-d10: $83.8 \% \pm 10.5 \%$, 屈-d12: $93.2 \% \pm 9.1 \%$, 芢-d12: $88.9 \% \pm$ $10.1 \%$, 检出限为 $1.5 \sim 9.3 \mathrm{ng} / \mathrm{g}$, 符合美国 EPA 标准.

\section{2 结果和讨论}

\subsection{PAHs 的浓度和组成}

16 种 PAHs 在 24 个采样点均有检出, 具体浓度 如表 1 所示. 大清河、子牙河和漳卫南运河沉积物中 PAHs 总量的变化范围分别为 58.77 1346.01, 326.89 11296.66 和 $470.88 \sim 2315.19 \mathrm{ng} / \mathrm{g}$; 平均值分别为 $1249.72,2926.40$ 和 $1049.30 \mathrm{ng} / \mathrm{g}$; 中值分别为 $1184.91,1138.40$ 和 $719.75 \mathrm{ng} / \mathrm{g}$. 可见中值均小于平 均值, 说明大部分采样点 PAHs 的浓度是小于其平均 值的. 比较 3 条河流 PAHs 总量的平均值和中值, 可 见漳卫南运河浓度最低. 根据 2010 年海河流域水资 源公报显示, 漳卫南运河中的卫运河和漳卫新河均 为劣 $\mathrm{V}$ 类水质 ${ }^{[18]}$, 是海河南系中水质最差的河流. 但 是目前的研究显示漳卫南运河水体 ${ }^{[13]}$ 和沉积物的新 型有机污染并不严重, 应该首先治理常规污染物. 


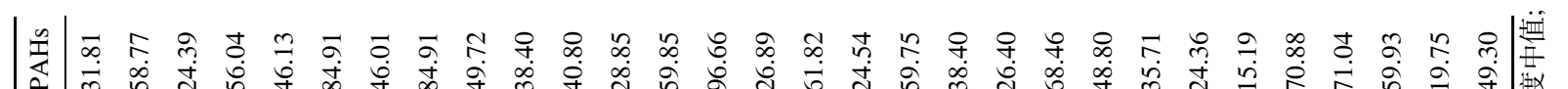
咥

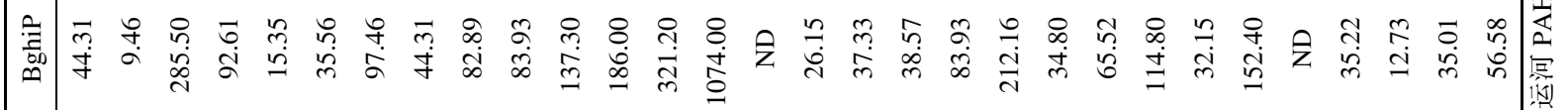

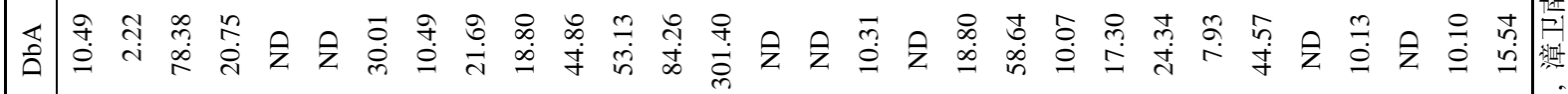

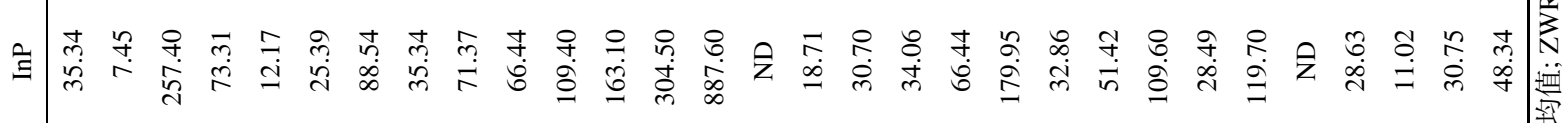

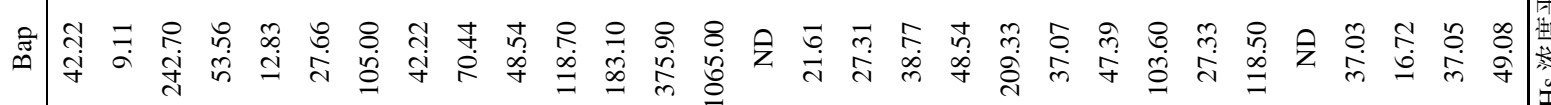

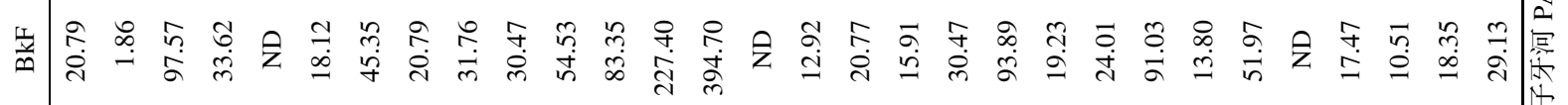

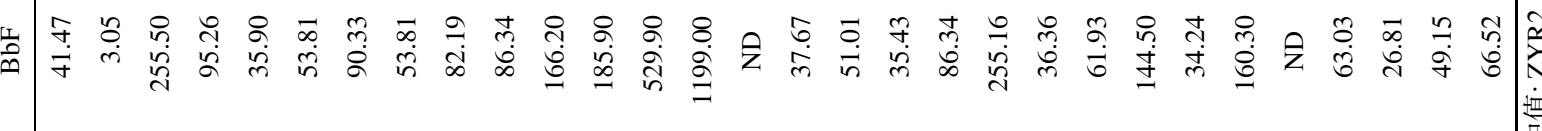

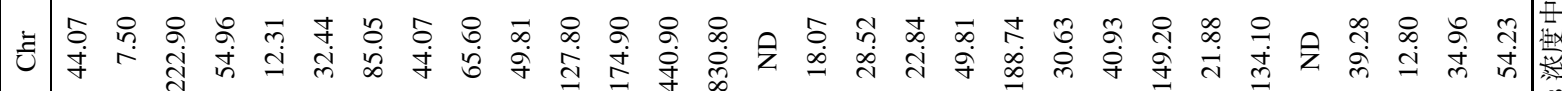

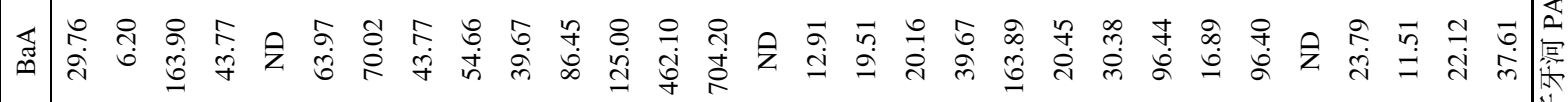

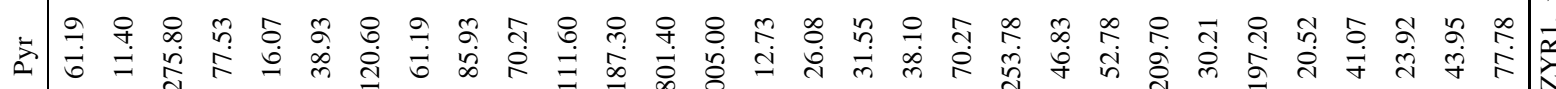
च 遭 玨 \#

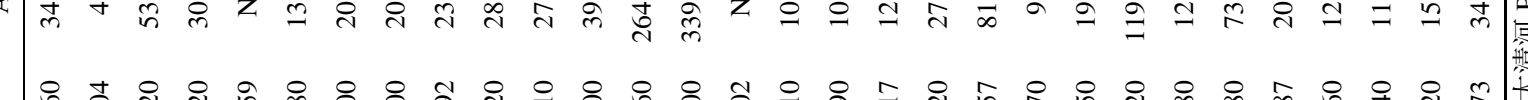

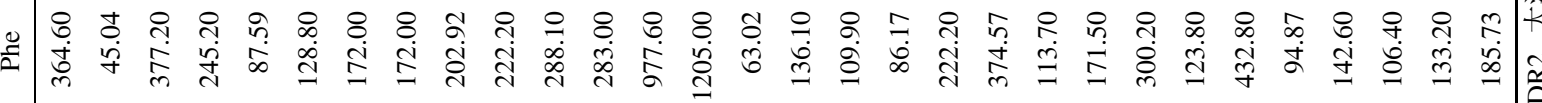

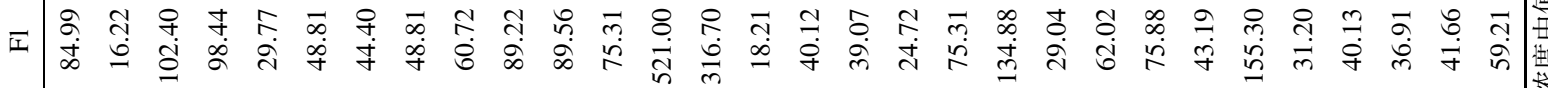

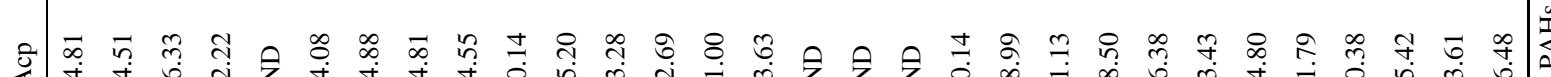

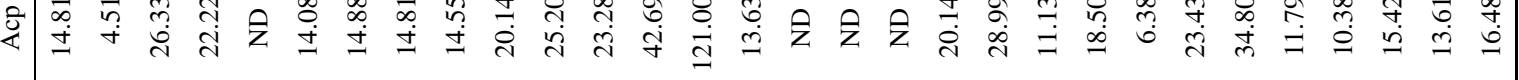

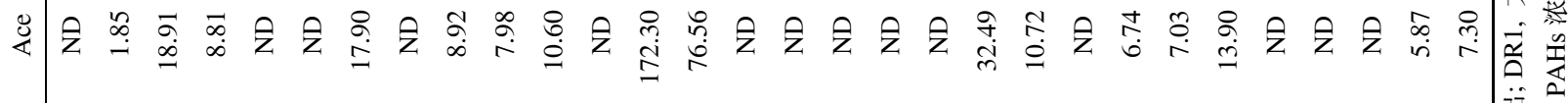

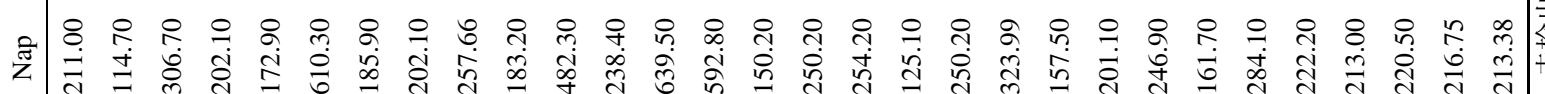

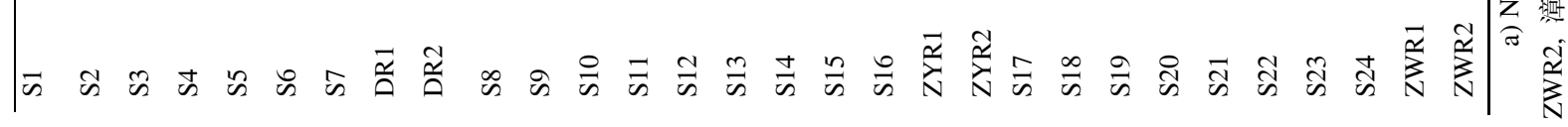


海河流域内不同水系相比, 海河南系的污染水 平要高于滦河水系和徒骇马-颊河水系, 但是低于海 河天津段. 由于多环芳烃属于难降解性的机物污染 物, 因此沉积物中的 PAHs 可以反映采样点历史的污 染情况 ${ }^{[19]}$. 天津是一个古老的大型工业城市, 并且 具有华北地区最大的港口, 而㴒河水系和徒骇-马颎 河水系则是主要的农业基地, 可见海河流域内 PAHs 的分布与地区的工业化水平是相一致的. 与其他河 流相比, 海河流域河流表层沉积物 PAHs 浓度远高于 国内外很多河流, 例如 Malyasia 河、Hyeongsan 河、 长江、黄河等(表 2), 说明海河流域 PAHs 污染整体处 于世界较高水平.

从 16 种 PAHs 的组成来看, 大部分采样点主要 是由 Na, Phe 和 Flu 组成, 其平均浓度分别为 267.77, 261.56 和 $191.37 \mathrm{ng} / \mathrm{g}$. 在邯単(S11)和艾兴庄(S12)Pyr, $\mathrm{BaA}, \mathrm{Chr}, \mathrm{BbF}, \mathrm{BaP}, \mathrm{InP}, \mathrm{BghiP}$ 也具有较高的浓度. 从各环 PAHs 的组成来看(图 2), 2 环、3 环、4 环、5 环、6 环 PAHs 所占的比例分别为 $25.32 \%, 27.22 \%$, $22.62 \%, 14.89 \%$ 和 $9.96 \%$. 可见大部分采样点主要 是由 2 环、3 环和 4 环 PAHs 组成的, 这与 $\mathrm{Fu}$ 等人 ${ }^{[25]}$ 对贾鲁河的检测结果一致. 但是保定 (S3)、大清河河口 $(\mathrm{S} 7)$ 、石家庄 $(\mathrm{S} 10)$ 、艾兴庄 $(\mathrm{S} 12)$ 和新乡 $(\mathrm{S} 19)$ 主要是 由 5 环和 6 环 PAHs 组成的. 在高温燃烧过程中产生 的 PAHs 多由中、高环(4 环、5 环、6 环)PAHs 组成, 一般认为其主要污染源为城市或工业污水 ${ }^{[26]}$; 石油 类产品泄漏等非高温过程中产生的 PAHs 多由低环

表 2 国内外河流沉积物 PAHs 浓度

\begin{tabular}{|c|c|c|c|c|}
\hline $\begin{array}{l}\text { 地 } \\
\text { 区 }\end{array}$ & 地点 & $\begin{array}{l}\text { PAHs } \\
\text { 种类 }\end{array}$ & 含量(ng/g) & $\begin{array}{l}\text { 参考 } \\
\text { 文献 }\end{array}$ \\
\hline \multirow{3}{*}{$\begin{array}{l}\text { 国 } \\
\text { 外 }\end{array}$} & Athabasca River, Canada & 16 & $10 \sim 34700$ & {$[20]$} \\
\hline & Milaysia River & 16 & $4 \sim 924$ & {$[21]$} \\
\hline & Hyeongsan River, Korea & 16 & $5.30 \sim 7680$ & [17] \\
\hline \multirow{9}{*}{$\begin{array}{l}\text { 国 } \\
\text { 内 }\end{array}$} & 钱塘江 & 15 & $91 \sim 614$ & {$[22]$} \\
\hline & 长江武汉段 & 16 & 72.4 995.2 & {$[23]$} \\
\hline & 黄河中下游 & 16 & $31 \sim 133$ & {$[24]$} \\
\hline & 大辽河 & 28 & $102.9 \sim 3419.2$ & [16] \\
\hline & 天津市内河流 & 16 & $787 \sim 1943000$ & [9] \\
\hline & 海河天津段 & 16 & 774.8 255371.91 & {$[10]$} \\
\hline & 徒骇-马颊河水系 & 9 & $311.69 \sim 3736.32$ & {$[11]$} \\
\hline & 㴒河水系 & 20 & $20.9 \sim 287$ & {$[12]$} \\
\hline & 海河南系 & 24 & $258.77 \sim 11296.66$ & 本研究 \\
\hline
\end{tabular}

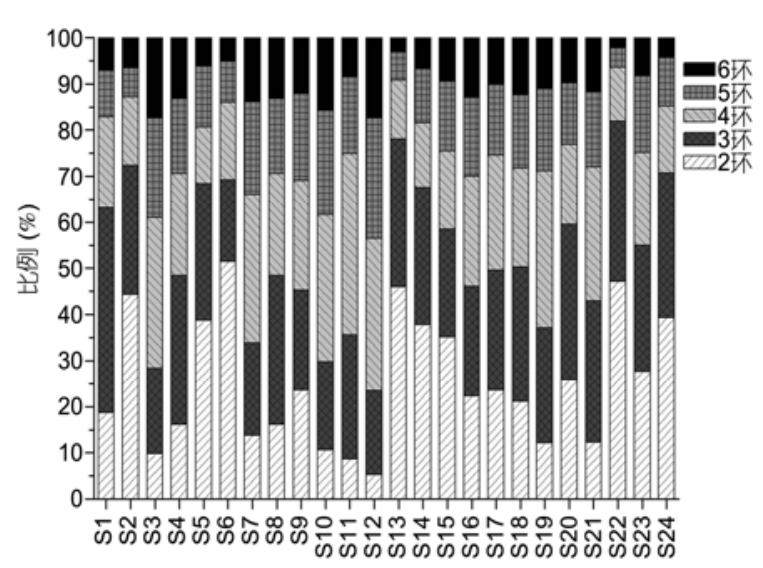

图 2 各采样点 PAHs 浓度组成结构

(2 环、3 环)PAHs 组成 ${ }^{[16]}$. 因此大部分采样点 PAHs 的 主要来源是石油类产品泄漏; S3, S7, S10, S12 和 S19 的 PAHs 主要来源于工业和城市污染排放.

\subsection{PHAs 分布}

海河南系沉积物 PAHs 的分布如图 3 所示. 大清 河中, PAHs 浓度最低点为西大洋水库(S2), 是保定市 的主要水源地; 最高浓度出现在府河下游(S3), 受保 定市城市生活和工业污水影响严重 ${ }^{[27]}$. 从分布来看, 污染严重的采样点集中在河流中下游地区, 其主要 原因可能是中下游地区分布有保定、天津等大城市. 这种分布特点与黄河是相一致的 ${ }^{[24]}$. 对于子牙河, 沉积物 PAHs 最高浓度出现在艾兴庄(S12, 11296.66 $\mathrm{ng} / \mathrm{g}$ ), 位于邢台附近. 邢台是一个大型工业城市, 面 积 $12486 \mathrm{~km}^{2}$, 人口 670 万人, 以制造业和煤盐化工 业著称. 艾兴庄的 PAHs 污染可能是受邢台市生活和 工业污水的影响. 子牙河 PAHs 浓度相对较低的采样

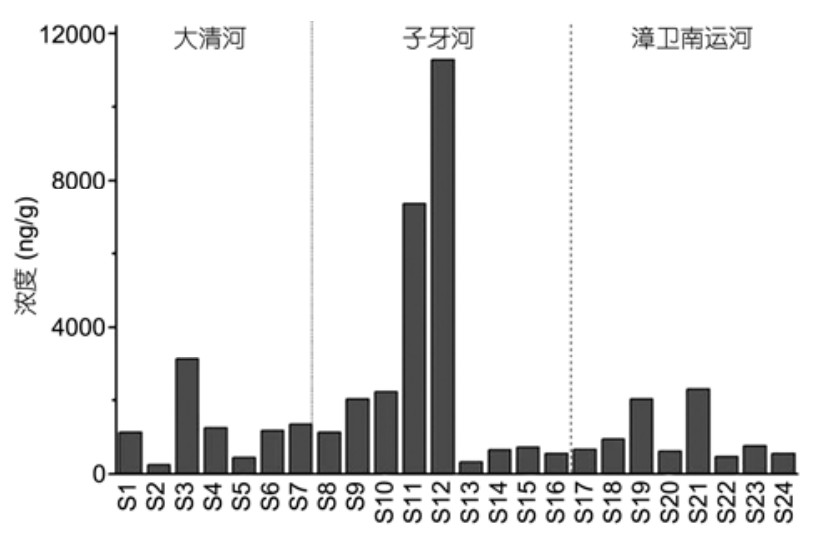

图 3 海河南系沉积物中 PAHs 的分布 
点多位于城市, 如沧州(724.54 ng/g)、石家庄(2228.85 $\mathrm{ng} / \mathrm{g}$ ). PAHs 最低浓度检出点为衡水湖 (326.89 ng/g), 其次为河口 $(559.75 \mathrm{ng} / \mathrm{g})$. 受采矿工业城市邯郸的影 响，子牙河中滏阳河河段是河北省污染最严重的河 段之一 ${ }^{[28]}$. 对于子牙河来讲，上、中游河段 PAHs 污 染相对严重, 下游和河口较轻. 漳卫南运河中 PAHs 浓度相对较高的采样点为新乡 $(\mathrm{S} 20,2035.71 \mathrm{ng} / \mathrm{g}$ ) 和 龙王庙 (S22, $2315.19 \mathrm{ng} / \mathrm{g}$ ), 相对较低的采样点为馆 陶(S23, $470.88 \mathrm{ng} / \mathrm{g})$ 和河口 $(\mathrm{S} 25,559.93 \mathrm{ng} / \mathrm{g})$. 龙王 庙位于卫运河的下游, 受上游城市新乡和鹤壁生活 和工业污水的影响; 新乡直接受城市自身交通、工业 污水等的影响, PAHs 浓度相对较高. 馆陶并不直接 受城市排污的影响, PAHs 浓度相对较低.

比较城市和农村地区的 PAHs 浓度(图4), 大清 河和漳卫南运河均表现为城市地区 PAHs 浓度高于 农村地区, 这种分布特征与马来西亚半岛的河流相 一致 ${ }^{[21]}$; 子牙河则表现为城市地区 PAHs 浓度低于农 村地区, 这主要是由艾兴庄极高的 PAHs 浓度值 (11296.66 ng/g)引起的, 其他位于农村地区采样点的 PAHs 浓度均较低(661.82 ng/g). 对比各河流上游水 库和最下游河口地区的 PAHs 浓度, 子牙河和漳卫南 运河河口的 PAHs 浓度均低于上游水库的浓度. 这可 能是因为这两条河流工业和农业用水量较大, 人海 流量均较小, 甚至为零 ${ }^{[13]}$; 且这两个河口均位于农 村地区, 受到上游来水和当地产生的 PAHs 影响均较 小. 与之相反, 大清河河口 PAHs 浓度相对较高, 可 能是因为大清河河口位于天津, 直接受港口石油泄 漏、城市工业和生活污水的影响.

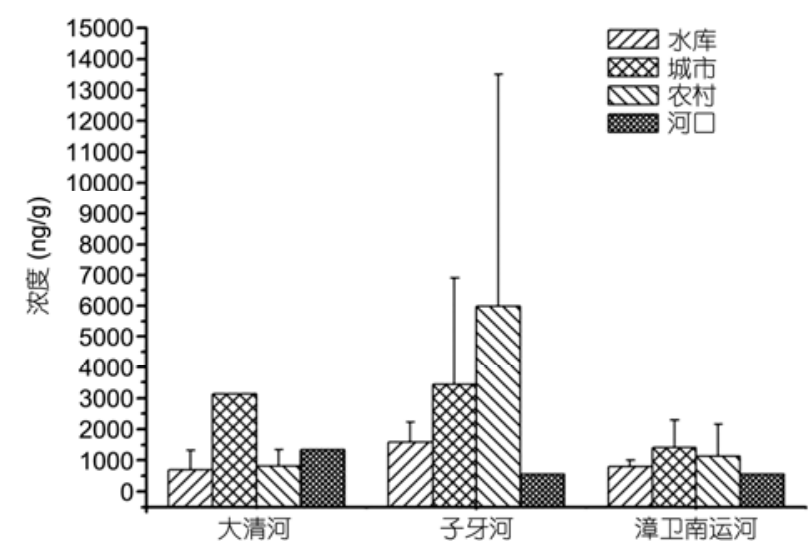

图 4 大清河、子牙河和漳卫南运河不同地区 PAHs 浓度 的比较
大清河、子牙河、漳卫南运河各采样点 PAHs 浓 度的变异系数分别为 $74 \%, 130 \%$ 和 $68 \%$, 说明 3 条河 流各采样点之间浓度差异较大. 大清河中 PAHs 污染 相对严重的采样点位于河流中下游地区，子牙河和 漳卫南运河则位于上中游地区. 但是 3 条河流 PAHs 浓度的分布均与城市的分布相一致，总体来说城市 地区直接受工业和生活污水、交通排放等的影响, PAHs 浓度高于农村地区. 在海河南系, 受 PAHs 污 染严重的河段为府河、大清河水系下游、滏阳河和卫 运河, 这些河段均受到城市交通和污水排放的影响.

\section{3 生态风险评价}

积累在沉积物中的 PAHs 可被沉水植物利用 ${ }^{[29]}$, 例如香蒲和芦苇, 从而进人水生食物网 ${ }^{[30]}$, 因此沉 积物中的 PAHs 对水生态系统健康是一种潜在的风 险源，可用生态风险评价来表征这种风险 ${ }^{[31]}$. Kalf 等 人 ${ }^{[32]}$ 于 1997 年提出用风险熵值 (RQ, Risk Quotient) 的方法来评价 PAHs 的生态风险, Cao 等人 ${ }^{[12]}$ 于 2010 年通过引人毒性系数对这种方法进行了改进. 本研 究中采用这种改进的风险摘值法对海河南系沉积物 中 PAHs 进行生态风险评价, 具体公式如下:

$$
\mathrm{RQ}=\frac{C_{\mathrm{PAHs}}}{C_{\mathrm{QV}}},
$$

式中, $C_{\mathrm{PAHs}}$ 为介质中 $\mathrm{PAHs}$ 的浓度; $C_{\mathrm{QV}}$ 为响应介质 中 PAHs 的风险标准值 ${ }^{[32]}$, 使用的是 Kalf 提出的最低 风险浓度(negligible concentrations, NCs) 和最高风险 浓度值(maximum permissible concentrations, MPCs), 具体见表 3. 最低风险浓度表示低于此浓度对生态系 统的负面影响是可以忽略的; 最高风险浓度表示高 于此浓度则会对生态系统产生较大的负面影响 ${ }^{[33]}$. 因此通过上述公式可进一步得到:

$$
\begin{gathered}
\mathrm{RQ}_{\mathrm{NCs}}=\frac{C_{\mathrm{PAHs}}}{C_{\mathrm{QV}(\mathrm{NCs})}}, \\
\mathrm{RQ}_{\mathrm{MPCs}}=\frac{C_{\mathrm{PAHs}}}{C_{\mathrm{QV}(\mathrm{MPCs})}},
\end{gathered}
$$

式中, $\mathrm{RQ}_{\mathrm{NCs}}$ 和 $\mathrm{RQ}_{\mathrm{MPCs}}$ 分别表示低风险熵值和高风险 熵值; $C_{\mathrm{QV}(\mathrm{NCs})}$ 表示相应介质中 PAHs 的低风险浓度值; $C_{\mathrm{QV}(\mathrm{MPC})}$ 表示相应介质中 PAHs 的高风险浓度值. 16 种 PAHs 总的风险熵值计算公式如下:

$$
\mathrm{RQ}_{\sum \mathrm{PAHs}}=\sum_{i=1}^{n=16} \mathrm{RQ}_{i} \quad\left(\mathrm{RQ}_{i} \geqslant 1\right),
$$




$$
\begin{array}{cc}
\mathrm{RQ}_{\sum \mathrm{PAHs}(\mathrm{NCs})}=\sum_{i=1}^{n=16} \mathrm{RQ}_{i(\mathrm{NCs})} \quad\left(\mathrm{RQ}_{i(\mathrm{NCS})} \geqslant 1\right), \\
\mathrm{RQ}_{\sum \mathrm{PAHs}(\mathrm{MPCs})}=\sum_{i=1}^{n=16} \mathrm{RQ}_{\mathrm{i}(\mathrm{MPC})} \quad\left(\mathrm{RQ}_{i(\mathrm{MPCs})} \geqslant 1\right) .
\end{array}
$$

各 PAHs 单体的高风险浓度和低风险浓度值如 表 3 所示, 风险等级的划分标准如表 4 所示.

16 种单体 PAHs 的低风险熵值均大于 1.0 ; 除 Nap 和 Pyr 外, 其他 14 种单体 PAHs 的高风险熵值均 小于 1 . 因此 Nap 和 Pyr 为高生态风险, 其他 14 种单 体 PAHs 均为中等生态风险. 海河南系各采样点总 PAHs 的低风险熵值和高风险熵值如图 5 所示. 西大

\section{表 3 单体 PAHs 的最低和最高风险浓度值 $(\mathrm{ng} / \mathrm{g})$}

\begin{tabular}{lcc||ccr}
\hline PAHs & NCs & MPCs & PAHs & NCs & MPCs \\
\hline Nap & 1.4 & 140 & BaA & 3.6 & 360 \\
Ace & 1.2 & 120 & Chr & 107 & 10700 \\
Acp & 1.2 & 120 & BbF & 3.6 & 360 \\
Fl & 1.2 & 120 & BkF & 24 & 2400 \\
Phe & 5.1 & 510 & BaP & 27 & 2700 \\
An & 1.2 & 120 & DbA & 27 & 2700 \\
Flu & 26 & 2600 & InP & 59 & 5900 \\
Pyr & 1.2 & 120 & BghiP & 75 & 7500 \\
\hline
\end{tabular}

表 4 单体 PAHs 和总 PAHs 生态风险等级划分

\begin{tabular}{lcc}
\hline 单体 $\mathrm{PAHs}$ & $\mathrm{RQ}_{(\mathrm{NCs})}$ & $\mathrm{RQ}_{(\mathrm{MPCs})}$ \\
\hline 低风险 & 0 & \\
中等风险 & $\geqslant 1$ & $<1$ \\
高风险 & & $\geqslant 1$ \\
\hline \hline 总 $\mathrm{PAHs}$ & $\mathrm{RQ}_{(\mathrm{NCs})}$ & $\mathrm{RQ}_{(\mathrm{MPCs})}$ \\
\hline 无风险 & 0 & \\
低风险 & $\geqslant 1 ;<800$ & 0 \\
中等风险-1 & $\geqslant 800$ & 0 \\
中等风险-2 & $<800$ & $\geqslant 1$ \\
高风险 & $\geqslant 800$ & $\geqslant 1$ \\
\hline
\end{tabular}

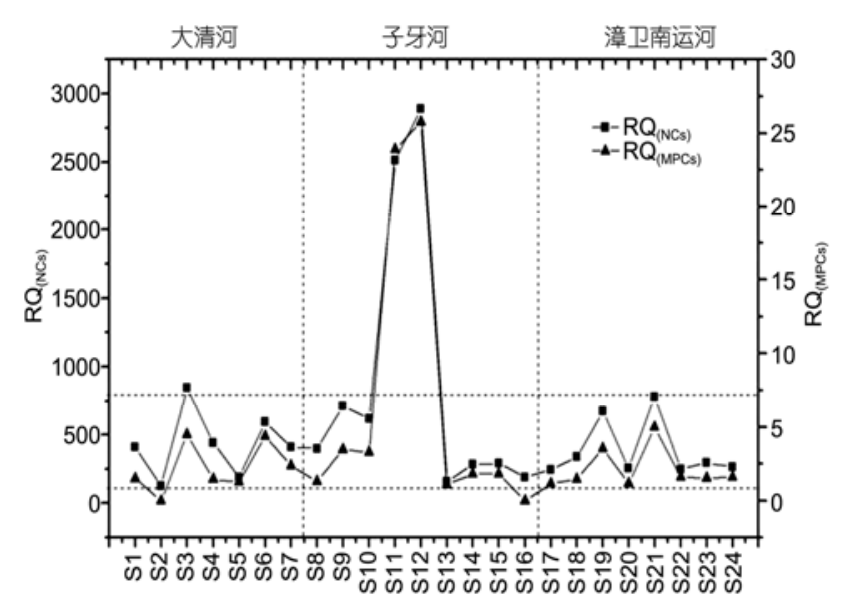

图 5 各采样点总 PAHs 的低风险摘值和高风险摘值

洋水库 (S2)和子牙河河口(S17)为低风险水平; 保定 $(\mathrm{S} 3)$ 、邯単 $(\mathrm{S} 11)$ 、艾兴庄 $(\mathrm{S} 12)$ 为高风险水平; 其他 19 个采样点均为中等风险水平, 因此府河和滏阳河 是 PAHs 生态风险最高的河段. Cao 等人 ${ }^{[12]}$ 用同样的 方法评价了㴒河水系的水体、沉积物和岸边土壤 PAHs 的生态风险以及漳卫南运河水体中 PAHs 的生 态风险. 与本研究的结果相比, 海河南系 PAHs 的生 态风险高于滦河水系, 漳卫南运河水体 PAHs 风险低 于沉积物.

\section{3 结论}

海河南系表层沉积物 PAHs 的浓度范围为 258.77 $11296.66 \mathrm{ng} / \mathrm{g}$, 组成以 2 环、 3 环、4 环 PAHs 为主. PAHs 浓度的分布与城市的分布相一致，府河、滏阳 河和卫运河是受 PAHs 污染最为严重的河段, 农村和 河口地区受 PAHs 污染相对较轻. 生态风险评价结果 显示, 16种单体 PAHs 中 Nap 和 Pyr 为高生态风险, 其 他 14 种为中等风险水平. 从各采样点总 PAHs 的生 态风险来看, 西大洋水库和子牙河河口为低生态风 险；保定、邯郸、艾兴庄为高生态风险水平.

\section{参考文献}

1 White K L. An overview of immunotoxicology and carcinogenic polycyclic aromatic hydrocarbons. J Environ Sci Health, 1986, 4: $163-202$

2 Heemken O P, Stachel B, Theobald N, et al. Temporal variability of organic micropollutants in suspended particulate matter of the River Elbe at Hamburg and the River Mulde at Dessau, Germany. Arch Enrion Contam Toxicol, 2000, 38: 11-31

3 Binelli A, Sarkar S K, Chatterjee M, et al. A comparison of sediment quality guidelines for toxicity assessment in the Sunderban wetlands (Bay of Bengal India). Chemosphere, 2008, 73: 1129-1137 
4 Christensen E R, Irwan A L, Razak A, et al. Sources of polycyclic aromatic hydrocarbons in sediment of the Kinnickinnic River, Wisconsin. J Great Lakes Res, 1997, 23: 61-73

5 Kelly B C, Lkonomou M G, Blair J D, et al. Food web-specific biomagnifications of persistent organic pollutants. Science, 2007, 317: 236-239

6 Guo G H, Wu F C, He H P, et al. Distribution characteristics and ecological risk assessment of PAHs in surface waters of China. Sci China Earth Sci, 2012, 55: 914-925

7 Yang Z F, Feng J L, Niu J F, et al. Release of polycyclic aromatic hydrocarbons from Yangtze River sediment cores during periods of simulated resuspension. Environ Pollut, 2008, 155: 366-374

8 Nobuyasu I, Shuji T, Michio K. Distribution of polycyclic aromatic hydrocarbons in a sediment core from the north basin of Lake Biwa, Japan. Org Geochem, 2010, 41: 845-852

9 Shi Z, Tao S, Pan B, et al. Contamination of rivers in Tianjin, China by polycyclic aromatic hydrocarbons. Environ Pollut, 2005, 134: 97-111

10 Jiang B, Zheng H L, Huang G Q, et al. Characterization and distribution of Polycyclic aromatic hydrocarbon in sediments of Haihe River, Tianjin, China. J Environ Sci, 2001, 19: 306-311

11 Liu F, Liu J, Chen Q, et al. Pollution characteristics, ecological risk and sources of polycyclic aromatic hydrocarbons (PAHs) in surface sediment from Tuhai-Majia River system, China. Proc Environ Sci, 2012, 13: 1301-1314

12 Cao Z G, Liu J L, Luan Y, et al. Distribution and ecosystem risk assessment of polycyclic aromatic hydrocarbons in the Luan River, China. Ecotoxicology, 2010, 19: 827-837

13 曹志国, 刘静玲, 王雪梅, 等. 漳卫南运河地表水中溶解态多环芳烃的污染特征、风险评价与来源辨析. 环境科学学报, 2010, 30: 254-260

14 Zhou J L, Hong H, Zhang Z, et al. Multi-phase distribution of organic micropollutants in Xiamen Harbour, China. Water Res, 2000, 34: 2132-2150

15 Mai B X, Fu J M, Zhang G, et al. Polycyclic aromatic hydrocarbons in sediments from the Pearl river and estuary, China: Spatial and temporal distribution and sources. Appl Geochem, 2001, 16: 1429-1445

16 Guo W, He M C, Yang Z F, et al. Distribution, partitioning and sources of polycyclic aromatic hydrocarbons in Daliao River water system in dry season, China. J Hazard Mater, 2009, 164: 1379-1385

17 Koh C H, Khim J S, Kannan K, et al. Polychlorinated dibenzo-p-dioxins (PCDDs), dibenzofurans (PCDFs), biphenyls (PCBs), and polycyclic aromatic hydrocarbons (PAHs) and 2,3,7,8-TCDD equivalents (TEQs) in sediment from the Hyeongsan River, Korea. Environ Pollut, 2004, 132: 489-501

18 中国环境保护总局. 地表水环境质量标准(GB3838-2002), 2002

19 Yunker M B, Macdonald R W. Alkane and PAH depositional history, sources and fluxes in sediments from the Fraser River Basin and Strait of Georgia, Canada. Org Geochem, 2003, 34: 1429-1454

20 Headley J V, Akre C, Conly F M, et al. Preliminary characterization and source assessment of PAHs in tributary sediments of the Athabasca River, Canada. Environ Forens, 2001, 2: 335-345

21 Zakaria M P, Takada H, Tsutsumi S, et al. Distribution of polycyclic aromatic hydrocarbons (PAHs) in rivers and estuaries in Malaysia: A widespread input of petrogenic PAHs. Environ Sci Technol, 2002, 36: 1907-1918

22 Chen Y Y, Zhu L Z, Zhou R B. Characterization and distribution of polycyclic aromatic hydrocarbon in surface water and sediment from Qiangtang River, China. J Hazard Mater, 2007, 141: 148-155

23 Feng C L, Xia X H, Shen Z Y, et al. Distribution and sources of polycyclic aromatic hydrocarbons in Wuhan section of the Yangtze River, China. Environ Monit Assess, 2007, 133: 447-458

24 Li G C, Xia X H, Yang Z F, et al. Distribution and sources of polycyclic aromatic hydrocarbons in the middle and lower reaches of the Yellow River, China. Environ Pollut, 2006, 144: 985-993

25 Fu J, Sheng S, Wen T, et al. Polycyclic aromatic hydrocarbons in surface sediments of the Jualu River. Ecotoxicology, 2011, 20: 940-950

26 Ko F C, Baker J, Fang M D, et al. Composition and distribution of polycyclic aromatic hydrocarbons in the surface sediments from the Susquehanna River. Chemosphere, 2007, 66: 277-285

27 Qiu R Z, Li Y X, Yang Z F, et al. Influence of water quality change in Fu River on wetland Baiyangdian. Front Earth Sci China, 2009, 3: 397-401

28 张景森, 张静, 张景广, 等. 人为因素对滏阳河邯䣋段河流水化学的影响. 河北工程大学学报(自然科学版), 2010, 27: 40-45

29 秦宁, 朱妲, 吴文婧, 等. 多环芳烃在小白洋淀挺水植物中的分布、组成及其影响因素. 湖泊科学, 2010, 22: 49-56

30 Liu A X, Lang Y H, Xue L D, et al. Probabilistic ecological risk assessment and source apportionment of polycyclic aromatic hydrocarbons in surface sediments from Yellow Sea. Bull Environ Contam Toxicol, 2009, 83: 681-687

31 Wu B, Zhang R, Chen S P, et al. Risk assessment of polycyclic aromatic hydrocarbons in aquatic ecosystems. Ecotoxicology, 2011, 20: 1124-1130 
32 Kalf D F, Crommentuijn T, Vandeplassche E J. Environmental quality objectives for 10 polycyclic aromatic hydrocarbons (PAHs). Ecotoxicol Environ Saf, 1997, 36: 89-97

33 Crommentuijn T, Sijm D, Bruijn J D, et al. Maximum permissible and negligible concentrations for some organic substances and pesticides. J Environ Manage, 2000, 58: 297-312

- 书 讯 .

\section{《海河流域水循环演变机理与水资源高效利用丛书》介绍}

强烈的人类活动正全面深度扰动着天然流域水循环 过程, 致使流域水循环在内在驱动力、循环结构和响应参 数等方面都呈现出明显的“天然-人工”二元演化特性，同时 引发一系列伴生的资源、生态与环境后效, 在我国北方地 区突出表现为缺水、水污染和生态系统退化三大共性问题. 要实现缺水地区供用水、水环境、水生态安全的国家目标, 必须实施以流域水循环为统一基础的水资源合理配置、有 效保护和高效利用, 从而在基础科学层面提出了水资源演 变、生态与环境演变的机理认知以及水资源利用效用基础 评价与调控的研究需求. 受人口、经济和水资源条件的影 响, 我国是世界上水资源短缺、水污染和水生态退化问题 最严重的国家之一. 国家重点基础研究发展计划(973 计 划), 以人类活动影响最为集中、各类水问题最为突出且在 全国经济社会发展格局中占有重要战略地位的海河流域为 研究区, 设置了“海河流域水循环演变机理与水资源高效 利用”项目(编号：2006CB403400), 由中国水利水电科学研 究院水资源所所长、中国工程院院士王浩作为首席科学家 负责. 2010 年 11 月海河 973 计划通过了科技部组织的验收, 被评为 “优秀”, 在资源环境领域排名第一, 取得了一系列 重大研究成果.

目前, 该成果将以《海河流域水循环演变机理与水资源 高效利用》丛书出版，已经获得国家出版基金支持. 该丛书 由王浩院士任主编. 王浩院士长期从事水文水资源领域研 究, 在流域水循环的基础认知模式与模拟技术、水资源评 价与配置理论与方法、水资源工程系统规划方法等方面取 得了一系列的创新性突破. 丛书编委还包括康绍忠院士、 清华大学陈吉宁校长、欧阳志云研究员等多位知名学者.

丛书以流域水循环演变机理与水资源高效利用为研 究对象, 选取我国北方典型缺水流域海河流域为研究区域, 以增强我国缺水流域水安全保障的基础科学支持能力为总 目标; 通过强人类活动干扰下的流域水循环及伴生过程演 变机理与规律的揭示, 为人类活动密集的缺水流域水循环
及生态与环境过程的整体调控奠定科学基础; 通过流域水 循环及其伴生过程综合模拟系统的构建, 发展变化环境下 “水-生态-环境”耦合过程的模拟技术; 通过水资源利用效 用评价理论与方法的提出, 丰富现代水资源规划的基础理 论与方法; 通过面向和谐社会的流域水循环整体多维调控 的理论、阈值与模式的提出, 形成缺水地区水资源高效利 用和促进人水和谐的调控定量标准集与方案.

该丛书内容突出了 3 方面的基础性和创新性特色：一 是突出了人类活动对于流域水循环和水资源演变的影响, 原创性地构建了 “自然-社会” 二元水循环与水资源的演化 基础理论; 二是突出了水循环及其伴生过程综合演变机理 与过程模拟, 变革了传统单一过程演化原理与过程模拟技 术; 三是突出了基于水循环的水资源高效利用机制与综合 调控模式，创新了节水和水资源调控的基础模式. 该项目 成果已在国家、流域和地方水资源与生态环境保护规划实 践得到广泛应用, 获得国内外同行的高度评价和认可, 有 效提升了我国水文水资源的国际影响. 丛书充分反映了我 国在工程技术领域最先进的水平和研究成果, 强调原创性, 内容涵盖了海河流域水资源问题的几乎全部方面. 丛书通 过对海河流域水资源的研究, 为我国的水资源利用献言献 策，并将对国民经济、社会发展产生重大影响.

丛书共包括“海河流域农田水循环过程与农业高效用 水机制”、“海河流域水环境安全问题与对策”、“海河流域 二元水循环模式与水资源演变机理”、“基于 ET 的水资源 与水环境综合管理规划”、“海河流域城市水循环模型”、“海 河流域生态系统演变、生态效应及其调控方法”等 25 分册, 字数约达 1500 万字.

科学出版社为该丛书成立了专门项目组, 由出版社高 层领导主抓、分社社长重点负责; 做重点营销; 联合作者, 加大项目的市场宣传力度, 拟 3 年里出版齐全, 敬请读者 期待.

(本刊讯) 